\title{
Piperidine nitroxide Tempol enhances cisplatin-induced apoptosis in ovarian cancer cells
}

\author{
MENG WANG ${ }^{1}$, KEYI LI $^{1}$, ZHIWEI ZOU ${ }^{1}$, LINLIN LI ${ }^{1}$, LINGQUN ZHU ${ }^{1}$, QIANLI WANG ${ }^{1}$, \\ WENWEN GAO ${ }^{1}$, YING WANG ${ }^{1}$, WENHUA HUANG ${ }^{2}$, RUIYUAN LIU ${ }^{3}$, KAITAI YAO ${ }^{1}$ and QIUZHEN LIU ${ }^{1,4}$ \\ ${ }^{1}$ Cancer Research Institute, School of Basic Medical Science; ${ }^{2}$ Department of Anatomy, School of Basic Medical Science; \\ ${ }^{3}$ Science Department of Chemistry, School of Pharmaceutical Sciences; ${ }^{4}$ Guangzhou Key Laboratory of \\ Tumor Immunology Research, Southern Medical University, Guangzhou, Guangdong 510515, P.R. China
}

Received July 3, 2016; Accepted May 11, 2018

DOI: $10.3892 / \mathrm{ol} .2018 .9289$

\begin{abstract}
A nitroxide radical, Tempol (Tempol, TPL), is usually used as an antioxidative agent clinically, whereas the mechanism underlying its pro-oxidative effect has not been thoroughly investigated. The present study investigated the pro-oxidative effect of TPL on the inhibition of cellular proliferation and its role in enhancing the effect of anticancer drug cisplatin (DDP) on the induction of apoptosis in ovarian cancer cells. Cell viability and proliferation were evaluated by MTT assay. Cell apoptosis was analyzed by flow cytometry (FCM) following staining with Annexin V/propidium iodide. Western blot analysis was performed to determine the expression levels of anti-apoptotic protein B-cell lymphoma-2 (Bcl-2) and pro-apoptotic protein $\mathrm{Bcl}-2$-associated $\mathrm{X}$ protein (Bax), and the Bcl-2:Bax expression ratio. Cellular reactive oxygen species (ROS) were labeled with dichlorofluorescin-diacetate and analyzed by FCM. The results revealed that cell viabilities of OVCAR3 and SKOV3 cells were decreased by TPL in dose-dependent manner at concentrations of 2 to $10 \mathrm{mM}$ after $48 \mathrm{~h}$ incubation. The cell proliferation rates of OVCAR3 and SKOV3 cells were suppressed by TPL at lower toxic concentrations of 1.5 and $1 \mathrm{mM}$, respectively, compared with the control group. The MTT assay indicated that the combination therapy significantly inhibited the cell proliferation of OVCAR3 cells compared with treatment with DDP alone. FCM demonstrated that the combination treatment increased the proportion of
\end{abstract}

Correspondence to: Professor Qiuzhen Liu, Cancer Research Institute, School of Basic Medical Science, Southern Medical University, 1838 Guangzhou Road North, Guangzhou, Guangdong 510515, P.R. China

E-mail: liuqiuzhen@126.com

Professor Ruiyuan Liu, Science Department of Chemistry, School of Pharmaceutical Sciences, Southern Medical University, 1838 Guangzhou Road North, Guangzhou, Guangdong 510515, P.R. China

E-mail: ruiyliu@smu.edu.cn

Key words: Tempol, cisplatin, combination treatment, apoptosis, reactive oxygen species, OVCAR3 cell line early apoptotic cells in OVCAR3 cells compared with single DDP treatment. Western blot analysis revealed that the combination treatment markedly decreased the Bcl-2:Bax expression ratio compared with treatment with DDP alone. Detection of cellular ROS expression levels demonstrated that the combination therapy significantly increased cellular ROS generation compared with the DDP-only therapy. These data indicated that TPL increased the effect of DDP on inducing apoptosis in OVCAR3 cells.

\section{Introduction}

Ovarian cancer is a major malignant tumor type affecting the female reproductive system, which has the highest mortality rate of all gynecological tumors (1). Therapeutic drug resistance is a major factor of the chemotherapy failure observed in the treatment of ovarian cancer (2). Cisplatin (DDP) is preferentially used for chemotherapy in ovarian cancer in clinical practice; however, its efficacy is often restricted due to its dose-limiting toxicities, including bone marrow toxicity, nephrotoxicity and the development of drug resistance (3-5). Identifying a method to limit DDP toxicity while maintaining its efficacy is significantly important for successful chemotherapy in ovarian cancer (6). Numerous studies have evaluated that cancer cells, in comparison with normal cells, are under increasing levels of oxidative stress associated with an increased overall generation level of reactive oxygen species (ROS) $(7,8)$. The moderately increased expression levels of ROS in cancer cells may stimulate cellular proliferation and promote mutations and genetic instability $(9,10)$; however, excessive production of ROS may inflict damage to various cellular components, including DNA, protein and lipid membranes $(11,12)$. This increased intrinsic ROS stress in cancer cells provides a unique opportunity for killing the malignant cells, due to their vulnerability to additional ROS attack (13).

As a small molecular of nitroxide radicals, Tempol (TPL) has been utilized as a biophysical tool for electron paramagnetic resonance spectroscopy in numerous studies (14-16). TPL has an unpaired electron and undergoes rapid reversible transfer between 3 forms: Nitroxide, hydroxylamine and the oxoamonium cation (17). Therefore, TPL is a potential redox 
agent that may function as a reductive or oxidative agent depending on the concentration in the cell (18). The clinical application of TPL at $<1 \mathrm{mM}$ is usually as an antioxidative agent in the treatment of inflammation $(19,20)$, such as periodontitis in a rodent model (21). And TPL also has a clinical application in neurodegenerative diseases including including Alzheimer's disease, Parkinson's disease and Huntington's disease $(22,23)$, or hypertension $(24)$. In contrast to studies regarding the antioxidative effects of TPL, another study has indicated that TPL, at concentrations of $>1 \mathrm{mM}$, may serve as a pro-oxidant by producing ROS and oxidizing reduced transition metals (25). TPL is favorable for inhibiting the growth of neoplastic cells by increasing cellular ROS production $(25,26)$. Based on these data, the present study hypothesized that the pro-oxidative activity of TPL increased the antitumor effects of DDP by increasing cellular ROS production and inducing cell apoptosis. The present study investigated the potentiating effect of TPL with an antitumor drug, DDP, on cellular proliferation and apoptosis in ovarian cancer cells.

\section{Materials and methods}

Chemicals. Dulbecco's modified Eagle's medium (DMEM), trypsin and fetal bovine serum (FBS) were purchased from Gibco (Thermo Fisher Scientific, Inc., Waltham, MA, USA). PBS was obtained from Boster Biological Technology (Pleasanton, CA, USA). TPL was purchased from Tokyo Chemical Industry Co., Ltd. (Tokyo, Japan). Cisplatin and MTT were purchased from Sigma-Aldrich (Merck KGaA, Darmstadt, Germany). The Annexin V-fluorescein isothiocyanate (FITC) Apoptosis Detection kit was obtained from BD Biosciences (Franklin Lakes, NJ, USA). The primary antibodies used for western blot analysis were purchased from multiple companies: Anti-Bcl-2 and anti-Bax were obtained from Cell Signaling Technology, Inc. (Danvers, MA, USA) and anti-GAPDH was purchased from Sigma-Aldrich, Merck KGaA. Dichlorofluorescin-diacetate (DCFH-DA) was obtained from Sigma-Aldrich, Merck KGaA.

Cell culture. OVCAR3 and SKOV3 human ovarian cancer cell lines were purchased from Southern Medical University Cancer Institute (Guangzhou, China). Cells were cultured in DMEM supplemented with $10 \% \mathrm{FBS}$ at $37^{\circ} \mathrm{C}$ in a humidified incubator at $5 \% \mathrm{CO}_{2}$. Cells were routinely subcultured using $0.05 \%$ trypsin-EDTA solution.

Cell viability assay. Briefly, cells were seeded into 96-well plates at the density of $5 \times 10^{3}$ cells/well. Following incubation at $37^{\circ} \mathrm{C}$ in humidified incubator for $24 \mathrm{~h}$, the DMEM was removed and replaced with a fresh medium containing increasing concentrations of TPL $(2,4,6,8$ or $10 \mathrm{mM})$ and cultured at $37^{\circ} \mathrm{C}$ for $48 \mathrm{~h}$. In order to estimate the effect of TPL on cell proliferation, growth curve analyses of OVCAR3 and SKOV3 cells were performed. Cells were seeded into 96-well plates at the density of $1 \times 10^{3}$ cells/well and cultured at $37^{\circ} \mathrm{C}$ with TPL (1.5 Mm in OVCAR3 cells and $1 \mathrm{mM}$ in SKOV3 cells) for 5 days. To investigate the effect of combination treatment of TPL and DDP on OVCAR3 cells proliferation, cells were cultured with 6 concentrations of DDP $(1,2,4,8,16$ or $32 \mu \mathrm{M}$ ) at $37^{\circ} \mathrm{C}$ for $48 \mathrm{~h}$, and then $3 \mu \mathrm{M}$ DDP combined with
1.5 and $2 \mathrm{mM}$ TPL, respectively at $37^{\circ} \mathrm{C}$ for $48 \mathrm{~h}$. Following treatment, the medium was discarded, cells were washed with PBS once and $100 \mu \mathrm{l}$ MTT solution $(0.5 \mathrm{mg} / \mathrm{ml})$, which was diluted with $10 \%$ FBS and phenol red-free DMEM (Thermo Fisher Scientific, Inc.), was added to each well and incubated for $4 \mathrm{~h}$ at $37^{\circ} \mathrm{C}$. Subsequently, the solution was discarded, $50 \mu \mathrm{l}$ dimethyl sulfoxide was added to each well and the absorbance was evaluated at $490 \mathrm{~nm}$. All experiments were performed in triplicate.

Inverted phase contrast microscopy observation. OVCAR3 cells were seeded in 6 -well plates $\left(2 \times 10^{6}\right.$ cells/well $)$ and treated with $1.5 \mathrm{mM}$ TPL, $3 \mu \mathrm{M}$ DDP or a combination of TPL and DDP (1.5 mM TPL and $3 \mu \mathrm{M}$ DDP) at $37^{\circ} \mathrm{C}$ for $48 \mathrm{~h}$. Following a $48 \mathrm{~h}$ exposure to drug or control treatments, the cells were observed at x10 magnification in 22 fields of view $(18 \mathrm{~mm})$ using an inverted phase contrast microscope. Images were captured at magnification, x200.

Flow cytometry (FCM) analysis. Induction of apoptosis was determined using an Annexin V-FITC Apoptosis Detection kit, according to the manufacturer's protocol. OVCAR3 cells were seeded in culture dishes at the density of $2 \times 10^{5}$ cells/well and incubated at $37^{\circ} \mathrm{C}$ for $48 \mathrm{~h}$ with media containing $1.5 \mathrm{Mm}$ TPL or $3 \mu \mathrm{M}$ DDP or a combination of TPL and DDP $(1.5 \mathrm{mM}$ TPL and $3 \mu \mathrm{M}$ DDP). Annexin V-FITC-positive staining is a hallmark of early apoptosis, whereas late apoptosis and necrosis are indicated by additional positive nuclear staining with propidium iodide (PI). The cells were immediately detected with the probes by FCM analysis using FACS Aria II (BD Biosciences) and analyzed by FlowJo Software (FlowJo LLC, Ashland, OR, USA). Each sample was analyzed three times in three independent experiments.

Western blot analysis. OVCAR3 cells were treated with TPL ( $1 \mathrm{mM})$, DDP $(3 \mu \mathrm{M})$ or combination of $1 \mathrm{mM}$ TPL and $3 \mu \mathrm{M}$ DDP at $37^{\circ} \mathrm{C}$ for $48 \mathrm{~h}$. Following incubation, cells were digested with $0.05 \%$ trypsin-EDTA solution at $37^{\circ} \mathrm{C}$ for $3 \mathrm{~min}$, collected into a centrifuge tube and washed twice with cold PBS. Protein lysis buffer (50 $\mu \mathrm{l} / \mathrm{dish})$ made up of 1X protease inhibitors (Hangzhou Fude Biological Technology Co., Ltd., Hangzhou, China) and $1 \mathrm{mM}$ phenylmethanesulfonyl fluoride (Fude Biological Technology Co., Ltd.) was added to centrifuge tubes and cells were lyzed on ice for $10 \mathrm{~min}$. The concentration of the prepared protein was detected according to the manufacturer's protocol of the Bicinchoninic Acid Protein Assay kit (Thermo Fisher Scientific, Inc.). The whole cellular proteins $(50 \mu \mathrm{g})$ were then mixed with $5 \mathrm{X}$ SDS-PAGE sample loading buffer (Fude Biological Technology Co., Ltd.) and boiled at $95^{\circ} \mathrm{C}$ for $10 \mathrm{~min}$. The treated samples were subjected to $12 \%$ SDS-PAGE and transferred to polyvinylidene fluoride membranes (EMD Millipore, Billerica, MA, USA). Nonspecific binding was blocked using 5\% non-fat powdered milk (dissolved in PBS) at room temperature for $1 \mathrm{~h}$ and the blots were incubated overnight at $4^{\circ} \mathrm{C}$ with the following antibodies: Bcl-2 (cat. no. 3498; 1:1,000), Bax (cat. no. 14796; 1:3,000) and GAPDH (cat. no. G9545; 1:5,000). The following day, all the membranes were washed three times with PBS supplemented with $0.1 \%$ Tween-20 prior 
to incubation with the horseradish peroxidase-conjugated goat anti-rabbit IgG secondary antibody (cat. no. FD0128; 1:5,000; Fude Biological Technology Co., Ltd.) for $1 \mathrm{~h}$ at room temperature. Finally, the membranes were washed with PBS supplemented with $0.1 \%$ Tween-20 three times for 5 min each. The bands were visualized by chemiluminescence reagents according to the manufacturer's protocols (EMD Millipore) and visualized on the ChemiDoc XRS+ Imaging System (Bio-Rad Laboratories, Inc., Hercules, CA, USA). Image Lab Software (version 3.0; Bio-Rad Laboratories, Inc.) was used to quantify band densitometry. A total of three independent experiments were performed.

Evaluation of cellular ROS by FCM. For the evaluation of the expression levels of ROS, OVCAR3 cells that had been treated with $1.5 \mathrm{mM}$ TPL at $37^{\circ} \mathrm{C}$ for $12 \mathrm{~h}$ were harvested and washed twice with PBS. The cells were suspended in $0.5 \mathrm{ml}$ PBS and incubated with $20 \mu \mathrm{M}$ DCFH-DA, a cell membrane permeable fluorescence probe, for $30 \mathrm{~min}$ at $37^{\circ} \mathrm{C}$. Subsequently, the cells were washed and suspended in $0.5 \mathrm{ml}$ PBS for analysis. Fluorescence levels were detected by FCM analysis using FACS Aria II (BD Biosciences) and analyzed by FlowJo Software. Each sample was analyzed three times in three independent experiments.

Statistical analysis. Results represent data from triplicate experiments for each treatment group and are presented as the mean \pm standard deviation. Student's t-test was performed for comparisons between 2 groups and one-way analysis of variance with the Student-Newman-Keuls post-hoc test for comparisons between $>2$ groups. $\mathrm{P}<0.05$ was considered to indicate a statistically significant difference.

\section{Results}

TPL inhibits the proliferation of OVCAR3 and SKOV3 cells. Fig. 1A depicted the chemical structure of TPL. In order to investigate the effect of TPL on cell proliferation, the present study performed an MTT assay to evaluate cell viability following TPL treatment with concentrations $>1 \mathrm{mM}$. The cell viabilities of OVCAR3 and SKOV3 cells were suppressed by TPL in a dose-dependent manner. The half-maximal inhibitory concentration $\left(\mathrm{IC}_{50}\right)$ values of TPL in OVCAR3 and SKOV3 cells were 3.72 and $2.32 \mathrm{mM}$, respectively, after $48 \mathrm{~h}$ incubation (Fig. 1B). Based on the $\mathrm{IC}_{50}$, a low concentration of drug without cytotoxicity was used. Therefore, the present study selected the concentration of $1.5 \mathrm{mM}$ TPL in the OVCAR3 group and $1 \mathrm{mM}$ TPL in the SKOV3 group to analyze the effect of TPL on cell proliferation. Cell growth curves indicated that the proliferation rate of OVACR 3 cells was significantly inhibited by TPL, compared with the control group, from the third day (third day, $\mathrm{P}=0.0097$; fourth day, $\mathrm{P}=0.0113$; fifth day, $\mathrm{P}=0.0155$ ); the proliferation rate of $\mathrm{SKOV} 3$ cells was also inhibited by TPL, compared with the control group, from the third day (third day, $\mathrm{P}=0.0286$; fourth day, $\mathrm{P}=0.0239$; fifth day, $\mathrm{P}=0.0174$ ) (Fig. 1C). These results suggested that TPL at concentrations of $\geq 1 \mathrm{mM}$ were toxic and suppressed cell proliferation in OVCAR3 and SKOV3 cells.
TPL increases DDP-induced proliferation inhibition of OVCAR3 cells. It is universally recognized that DDP is the chemotherapeutic drug for ovarian cancer in clinical practice (28). MTT assays were used in the present study determined the $\mathrm{IC}_{50}$ of DDP in the experimental system. Fig. 2A indicated that the $\mathrm{IC}_{50}$ of DDP was $4.71 \mu \mathrm{M}$ following incubation for $48 \mathrm{~h}$. To investigate whether TPL increased the effect of DDP on cell proliferation inhibition, OVCAR3 cells were incubated with a combination of $3 \mu \mathrm{M}$ DDP and 1.5 or $2.0 \mathrm{mM}$ TPL. Each concentration of TPL significantly increased DDP-induced cell proliferation inhibition, compared with the signal DDP treatment group (Fig. 2B), suggesting that TPL improved the effect of DDP on inhibiting cell proliferation. When incubated with TPL alone, the higher concentration of $2.0 \mathrm{mM}$ revealed a slightly higher toxicity compared with low concentration of $1.5 \mathrm{mM}$ TPL, but no significant statistical difference was observed. Following treatment of TPL combined with DDP, the high TPL concentration group exhibited significant proliferation inhibition in OVCAR3 cells compared with the low TPL concentration group $(\mathrm{P}<0.05)$, indicating that the proliferation inhibition effect of TPL was more marked at higher concentrations.

Morphological observation of OVCAR3 cells following combination treatment of TPL and DDP. Morphological observations of OVCAR3 cells following treatment with TPL or DDP or the combination of two drugs are demonstrated in Fig. 3. OVCAR3 cells, cultured in the control group, were fibroblasts-like which had a long and flat shape with irregular protrusions. Following TPL treatment for $48 \mathrm{~h}$, the cell shape was not altered significantly, while the cell number was decreased compared with the control group. In the DDP treatment group, the cell shape changed, including some cells shriveling and others appearing round in shape. In the combination treatment group, the cell number was markedly decreased compared with the DDP-only treatment, and the majority of the cells were round in shape and had not attached to the culture dish. The combination treatment decreased cell proliferation of OVCAR3 cells more effectively compared with treatment with TPL or DDP alone.

TPL improves DDP-induced apoptosis of OVCAR3 cells. The effect of DDP in cancer therapy is dependent on the induction of cell apoptosis. To evaluate the apoptotic stages of the cells following stimulation with the combination treatment, FCM analysis was used to distinguish the early apoptotic cells stained with Annexin V-FITC and the late apoptotic cells stained with PI. Representative cytograms for each treatment group are presented in Fig. 4A. Stimulation of OVCAR3 cells with the combination of $1.5 \mathrm{mM}$ TPL and $3 \mu \mathrm{M}$ DDP for $48 \mathrm{~h}$ produced a significant increase in the percentage of early apoptotic

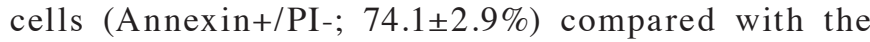
DDP alone treatment $(59.52 \pm 1.58 \%$; Fig. 4B; $\mathrm{P}=0.0121)$. The percentage of late apoptotic cells in the combination group (Annexin+/PI+; 5.43 $\pm 0.58 \%$ ) was similar to the DDP group $(7.29 \pm 2.3 \%$; Fig. 4B). This experiment indicated that TPL accelerated DDP-induced apoptosis, primarily reflected in the increase in proportion of early apoptotic cells. 
A<smiles>CON1C(C)(C)CC(O)CC1(C)C</smiles>

(4-hydroxy-2,2,6,6-tetramethylpiperidinooxyl)

C

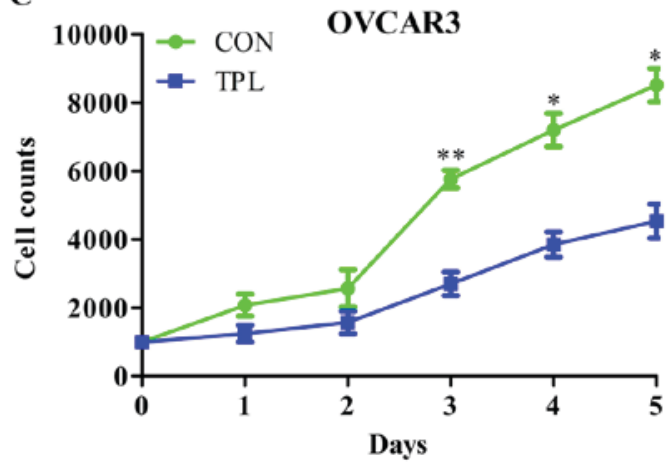

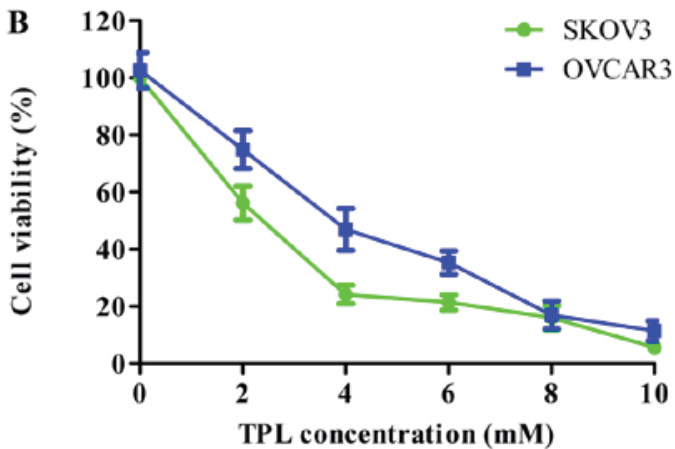

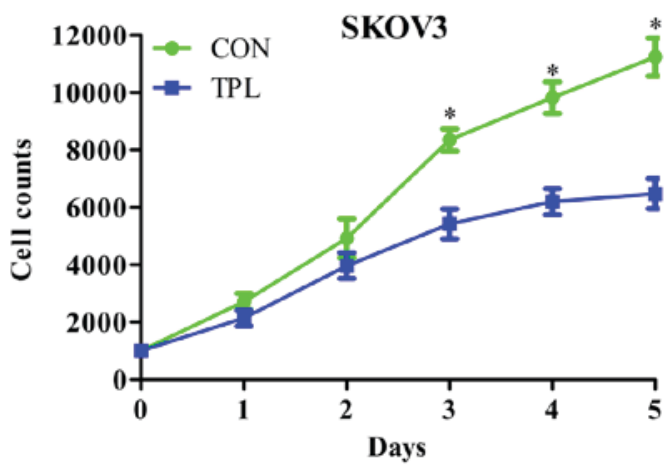

Figure 1. TPL inhibits the proliferation of OVCAR3 and SKOV3 cells. Cells were incubated with several concentrations of TPL (2, 4, 6,8 or $10 \mathrm{mM})$ for $48 \mathrm{~h}$. OVCAR3 and SKOV3 cells were incubated with TPL of 1.5 and $1 \mathrm{mM}$, respectively, for 5 days to estimate the cell proliferation. (A) Chemical structure of TPL. (B) Changes in cell viability following TPL treatment. (C) Changes in cell proliferation following TPL treatment. "P<0.05 and ${ }^{* *} \mathrm{P}<0.01$ vs. control group. TPL, Tempol; CON, control.
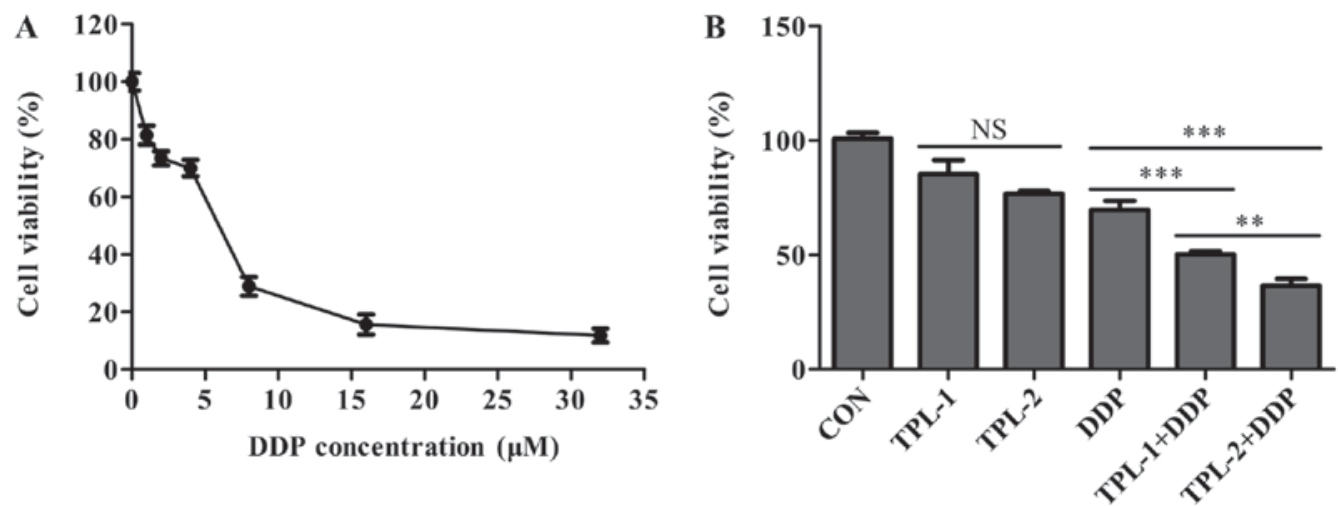

Figure 2. Effect of TPL on DDP-induced proliferation inhibition. OVCAR3 cells were incubated with increasing concentrations of DDP (1, 2, 4, 6, 8, 16 or $32 \mu \mathrm{M})$ for $48 \mathrm{~h}$. The proliferation of OVCAR3 cells with combination treatment of TPL (1.5 and $2 \mathrm{mM})$ and DDP $(3 \mu \mathrm{M})$ was increased compared with the DDP-only treatment. (A) Changes in cell viability following DDP treatment. (B) Changes in cell viability from the DDP and TPL alone treatments compared with the combination treatment. ${ }^{* *} \mathrm{P}<0.01$ and ${ }^{* * *} \mathrm{P}<0.001$ vs. corresponding DDP group. NS, non-significant; TPL, Tempol; DDP, cisplatin; CON, control TPL-1, 1.5 mM TPL; TPL-2, 2 mM TPL.

TPL decreases DDP-induced expression ratio of Bcl-2:Bax in OVCAR3 cells. The expression ratio of Bcl-2:Bax serves an important role in cellular apoptosis. To verify whether the combination treatment was able to increase the apoptosis rate of OVCAR3 cells, western blot analysis was used to detect the expression of anti-apoptotic protein Bcl-2 and pro-apoptotic protein Bax, and the expression ratio of Bcl-2:Bax. Fig. 5A depicted the protein expression after TPL treatment, DDP treatment and combination treatment. The data in Fig. 5B indicates that the combination treatment decreased the protein level of Bcl-2 and the expression ratio of Bcl-2:Bax induced by DDP $(\mathrm{P}=0.028)$. These results suggest that the TPL treatment significantly promoted DDP-induced apoptosis in OVCAR3 cells.

TPL increases the DDP-induced apoptosis through ROS generation in OVCAR3 cells. To investigate the potential mechanism of TPL-increased DDP-induced apoptosis in OVCAR3 cells, the cellular ROS generation induced by TPL and DDP in OVCAR3 cells was examined with DCFH-DA staining. As 
CON

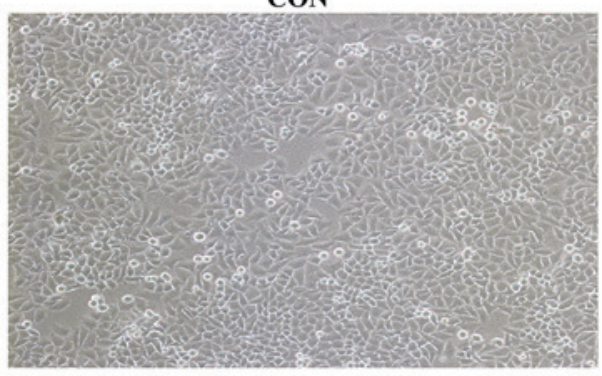

DDP

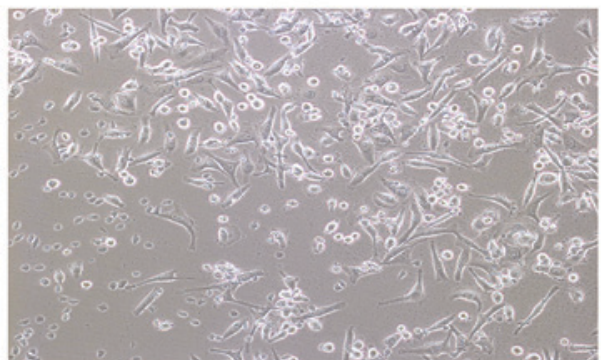

TPL

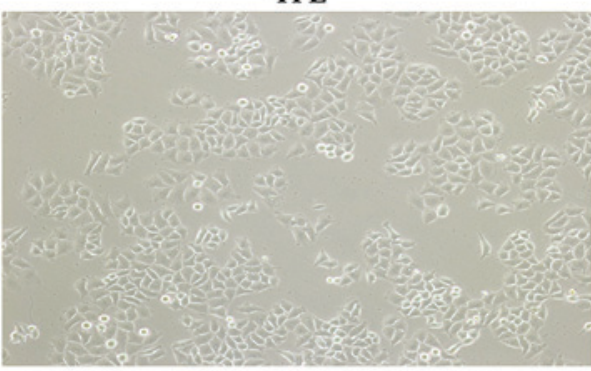

TPL+ DDP

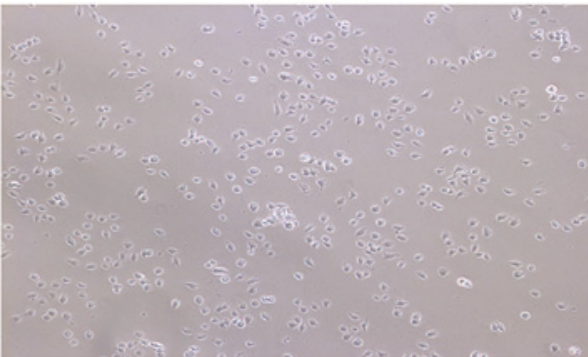

Figure 3. Morphological observations of OVCAR3 cells. The cell number decreased markedly following the combination treatment of $1.5 \mathrm{mM}$ TPL and $3 \mu \mathrm{M}$ DDP, and cell shapes were different from the DDP alone treatment. The microscopy image in each group is representative of three independent experiments in which 4 fields of view were randomly captured. All photos were captured at magnification, x200. CON, control; TPL, Tempol; DDP, cisplatin.

A
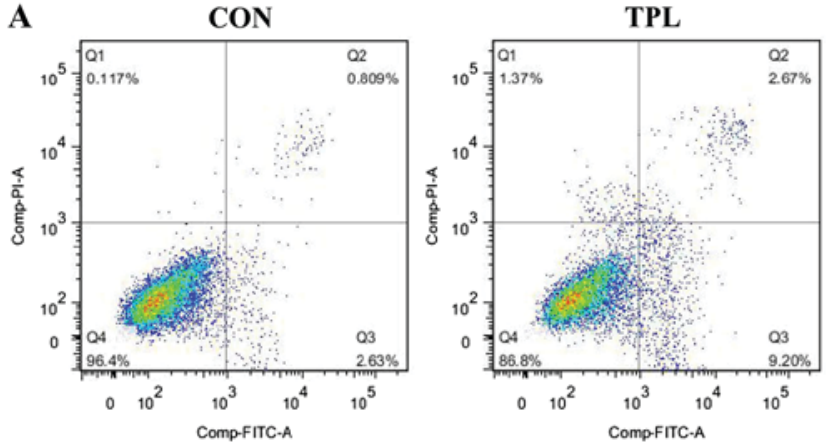

B

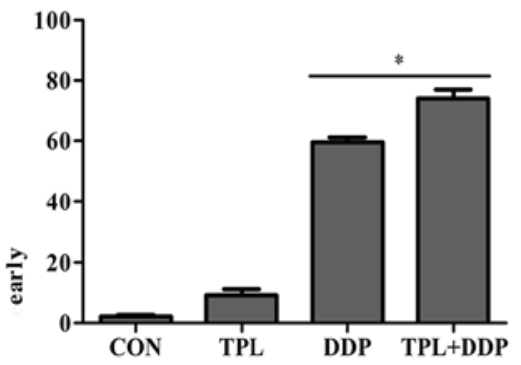

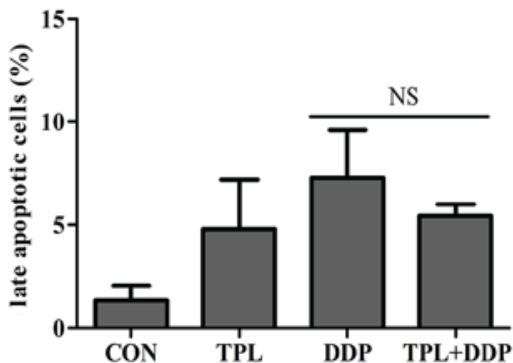

DDP

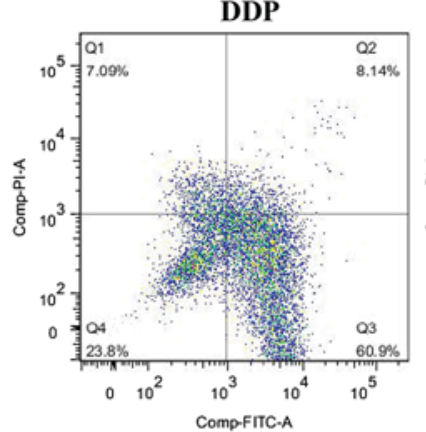

TPL+ DDP
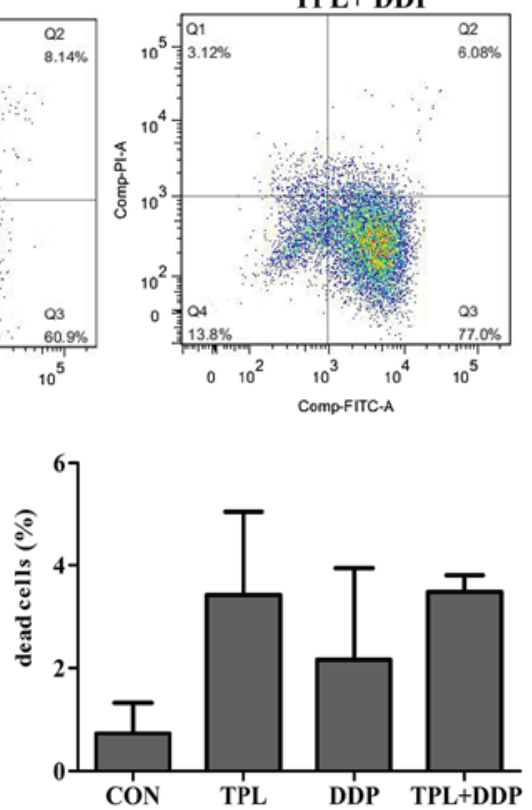

Figure 4. Effects of TPL on DDP-induced apoptosis in OVCAR3 cells. OVCAR3 cells were treated with $1.5 \mathrm{mM}$ TPL or $3 \mu \mathrm{M}$ DDP or a combination of the two drugs for $48 \mathrm{~h}$. Apoptosis was quantified using Annexin V/PI staining followed by flow cytometry analysis. (A) Representative graph for each experimental group. (B) Histograms demonstrating percentages of each cell population. Data are presented as the mean \pm standard deviation of triplicate experiments. ${ }^{*} \mathrm{P}<0.05$ vs. corresponding DDP group. NS, non-significant; CON, control; TPL, Tempol; DDP, cisplatin; PI propidium iodide; FITC, fluorescein isothiocyanate.

depicted in Fig. 6A, following treatment with TPL or DDP for $12 \mathrm{~h}$, TPL and DDP increased the fluorescence intensity of ROS in OVCAR 3 cells compared with the control group. In addition, the fluorescence intensity of ROS in the combined treatment group was significantly increased compared with the DDP alone group ( $\mathrm{P}=0.0035$; Fig. 6B). Therefore, it was concluded that TPL improved the cellular ROS production induced by DDP, suggesting that TPL-increased DDP-induced apoptosis may be associated with an increase in DDP-induced ROS generation.

\section{Discussion}

DDP chemotherapy is one of the primary treatments for ovarian cancer and has been applied for a number of years, despite the fact that DDP treatment alone does not demonstrate satisfactory effects in current clinical practice. Drug resistance has emerged as the major impediment to effective ovarian cancer therapy (3-5). Therefore, novel strategies that are able to improve the effects of DDP urgently required. TPL, a cyclic 
A

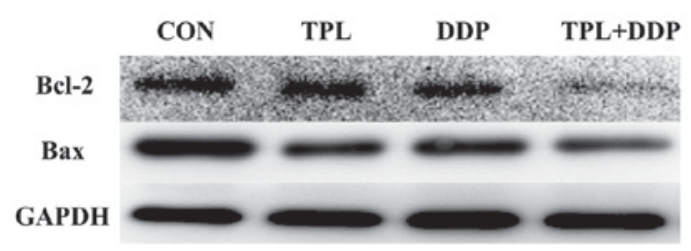

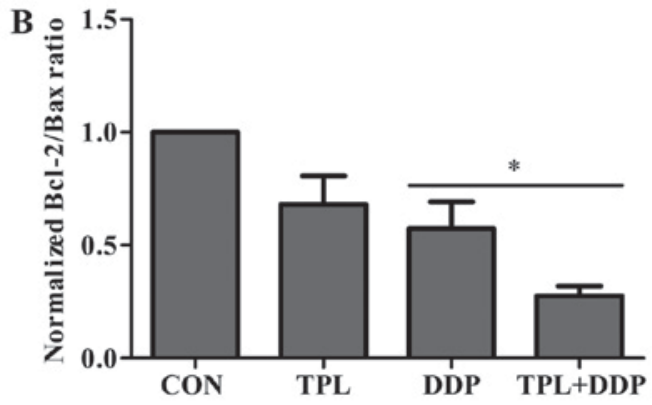

Figure 5. Effect of TPL on DDP-induced expression of Bcl-2 and Bax and the Bcl-2:Bax expression ratio in OVCAR3 cells. OVCAR3 cells were treated with $1.5 \mathrm{mM}$ TPL or $3 \mu \mathrm{M}$ DDP or a combination of the two drugs for $24 \mathrm{~h}$. Then, western blot analysis was used to detect the protein level of Bcl-2 and Bax and the Bcl-2:Bax expression ratio. GADPH was used as a positive control. (A) Representative images from western blot analysis performed for the detection of Bcl-2 and Bax. (B) Densitometric analyses of the Bcl-2:Bax expression ratio. Data are presented as the mean \pm standard deviation of triplicate experiments. ${ }^{*} \mathrm{P}<0.05$ vs. DDP alone treatment. CON, control; TPL, Tempol; DDP, cisplatin; Bcl-2, B-cell lymphoma 2; Bax, Bcl-2-associated X protein.
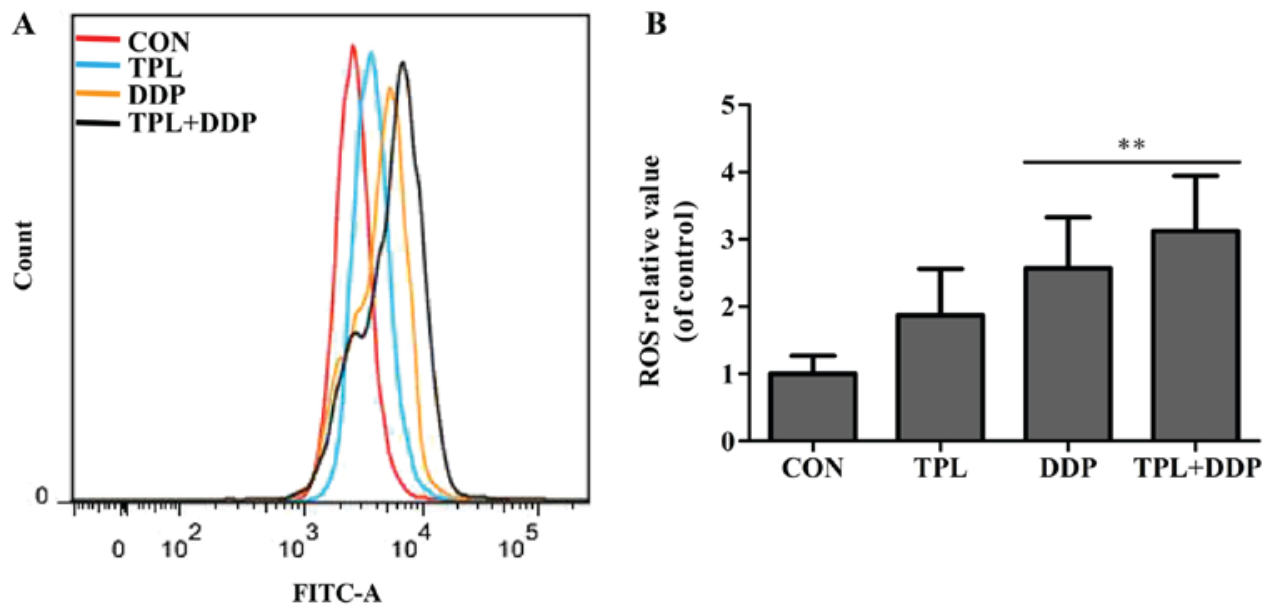

Figure 6. Effect of TPL on DDP-induced ROS generation in OVCAR3 cells. Cells were treated with $1.5 \mathrm{mM}$ TPL or $3 \mu \mathrm{M}$ DDP or a combination of the two drugs for $12 \mathrm{~h}$. The ROS level in OVCAR3 cells was determined with DCFH-DA by flow cytometry. (A) The representative graph of DCFH-DA flow cytometry. (B) Quantitative evaluations of ROS production. Data are presented as the mean \pm standard deviation of mean of triplicate experiments. ${ }^{* *} \mathrm{P}<0.01$ vs. corresponding DDP group. CON, control; TPL, Tempol; DDP, cisplatin; FITC, fluorescein isothiocyanate; ROS, reactive oxygen species; DCFH-DA, dichlorofluorescin-diacetate.

nitroxide, protects normal organs from oxidative damage and notably inhibits the growth of neoplastic cells, compared with the growth of normal cells (29), which suggests that TPL may be a promising agent for cancer treatment. The present study investigated whether TPL was able to potentiate the effect of DDP on chemotherapy-induced apoptosis in ovarian cancer cells. Firstly, the combination treatment of TPL and DDP significantly inhibited the proliferation of OVCAR3 cells, as indicated by MTT assay. Subsequently, FCM analysis indicated that the effect of DDP in inducing apoptosis was markedly increased following TPL and DDP combination therapy in OVCAR3 cells. This effect may provide the possibility of a decrease in the effective dose of DDP in clinical therapy, and consequent decrease in the dose-associated toxicity of DDP.

ROS generation, a hallmark of apoptosis induction, has been demonstrated to be associated with an inhibition of the mitochondrial respiration chain, leading to rupture of and alterations to the membrane potential of mitochondria (30). It has also been demonstrated that ROS generation consequently leads to the release of cytochrome $\mathrm{C}$ from the mitochondria to the cytosol, and activation of the mitochondrial apoptotic pathway (31). Bcl-2 and Bax serve important roles in regulating caspase-dependent and caspase-independent apoptosis, mediated by the mitochondrial pathway. These types of apoptosis are accompanied by an upregulation of Bax and downregulation of $\mathrm{Bcl}-2$, or downregulation of the Bcl-2:Bax expression ratio, and promotion of the formation of apoptosome (32). Western blot analysis demonstrated that co-treatment markedly decreased the protein level of Bcl-2 and the Bcl-2:Bax expression ratio compared with the DDP-only treatment. Previous studies demonstrated that TPL has an unpaired electron and interferes with the electron transport carriers in the mitochondria, particularly Complex I, leading to the formation of ROS $(25,27)$. The DCFH-DA staining assay in the present study indicated that TPL increased the cellular ROS generation induced by DDP. These results indicated that the combination treatment of TPL and DDP induced apoptosis through increasing the cellular ROS level in OVCAR3 cells. However, there are potential harmful interactions between TPL with enzyme complexes that may alter essential cell functions, including inhibition of glucose transport and impairing of mitochondrial adenosine 5'-triposphate production $(33,34)$. Therefore, the potential side effects of TPL may result in damage to the function of some normal cells. 
In conclusion, the present study identified that TPL increases the rate of DDP-induced apoptosis in OVCAR3 cells, highlighting the significant therapeutic implications of TPL combined with DDP in OC. Whether this combination will affect other types of human cancer cells similarly remains to be determined.

\section{Acknowledgements}

The authors thank Guangzhou Key Laboratory of Tumor Immunology Research, Southern Medical University, Guangzhou, China, for providing experimental platforms.

\section{Funding}

The present study was financially supported by the National Natural Science Foundation of China (grant no. 81472834), Guangzhou Science and Technology Research project (grant no. 201400000001-1), National Major Basic Research Program of China (grant no. 2010CB529401), National Natural Science Foundation of China (grant no. 61427807) and the Introduced Major Research and Development Project Funded by Fujian Province (grant no. 2012I2004).

\section{Availability of data and materials}

The datasets used and/or analyzed during the current study are available from the corresponding author on reasonable request.

\section{Authors' contributions}

MW participated in the design of the study, performed all experiments and wrote the manuscript. KL assisted performing cells cultures and western blotting. $\mathrm{ZZ}$ assisted performing flow cytometry analysis. LL assisted performing inverted phase contrast microscopy observation. QW, LZ and WG helped with the statistical analysis. YW, WH, RL and KY participated in the design of the study. QL conceived of the study and assisted editing the manuscript. All authors read and approved the final manuscript.

\section{Ethics approval and consent to participate}

Not applicable.

\section{Patient consent for publication}

Not applicable.

\section{Competing interests}

The authors declare that they have no competing interests.

\section{References}

1. SalehiF, Dunfield L, Phillips KP, Krewski D and Vanderhyden BC: Risk factors for ovarian cancer: An overview with emphas is on hormonal factors. J Toxicol Environ Health B Crit Rev 11: 301-321, 2008.

2. Markman M: Pharmaceutical management of ovarian cancer: Current status. Drugs 68: 771-789, 2008.

3. Mckeage MJ: Comparative adverse effect profiles of platinum drugs. Drug Saf 13: 228-244, 1995.
4. Aisner J, Jacobs M, Sinabaldi V, Gray W and Eisenberger M: Chemoradiotherapy for the treatment of regionally advanced head and neck cancers. Semin Oncol 21 (5 Suppl 12): S35-S44, 1994.

5. Ali BH and Al Moundhri MS: Agents ameliorating or augmenting the nephrotoxicity of cisplatin and other platinum compounds: A review of some recent research. Food Chem Toxicol 44: 1173-1183, 2006.

6. Santos NA, Catao CS, Martins NM, Curti C, Bianchi ML and Santos AC: Cisplatin-induced nephrotoxicity is associated with oxidative stress, redox state unbalance, impairment of energetic metabolism and apoptosis in rat kidney mitochondria. Arch Toxicol 81: 495-504, 2007.

7. Cairns RA, Harris IS and Mak TW: Regulation of cancer cell metabolism. Nat Rev Cancer 11: 85-95, 2011.

8. Kawanishi S, Hiraku Y, Pinlaor S and Ma N: Oxidative and nitrative DNA damage in animals and patients with inflammatory diseases in relation to inflammation-related carcinogenesis. Biol Chem 387: 365-372, 2006.

9. Janssen-Heininger YM, Mossman BT, Heintz NH, Forman HJ Kalyanaraman B, Finkel T, Stamler JS, Rhee SG and van der Vliet A: Redox-based regulation of signal transduction: principles, pitfalls, and promises. Free Radic Biol Med 45: 1-17, 2008.

10. Ames BN, Shigenaga MK and Hagen TM: Oxidants, antioxidants, and the degenerative diseases of aging. Proc Natl Acad Sci USA 90: 7915-7922, 1993.

11. Schafer ZT, Grassian AR, Song L, Jiang Z, Gerhart-Hines Z, Irie HY, Gao S, Puigserver P and Brugge JS: Antioxidant and oncogene rescue of metabolic defects caused by loss of matrix attachment. Nature 461: 109-113, 2009.

12. Perry G, Raina AK, Nunomura A, Wataya T, Sayre LM and Smith MA: How important is oxidative damage? Lessons from Alzheimer's disease. Free Radic Biol Med 28: 831-834, 2000.

13. Moloney JN and Cotter TG: ROS signalling in the biology of cancer. Semin Cell Dev Biol 80: 50-64, 2018.

14. Brasch RC, London DA, Wesbey GE, Tozer TN, Nitecki DE, Williams RD, Doemeny J, Tuck LD and Lallemand DP: Work in progress: Nuclear magnetic resonance study of a paramagnetic nitroxide contrast agent for enhancement of renal structures in experimental animals. Radiology 147: 773-779, 1983.

15. Tabaczar S, Talar M and Gwoździński K: Nitroxides as antioxidants-possibilities of their application in chemoprevention and radioprotection. Postepy Hig Med Dosw (Online) 65: 46-54, 2011 (In Polish).

16. Saito K, Takeshita K, Ueda J and Ozawa T: Two reaction sites of a spin label, TEMPOL (4-hydroxy-2,2,6,6-tetramethylpiperidine-N-oxyl), with hydroxyl radical. J Pharm Sci 92: 275-280, 2003.

17. Krishna MC, Grahame DA, Samuni A, Mitchell JB and Russo A: Oxoammonium cation intermediate in the nitroxide-catalyzed dismutation of superoxide. Proc Natl Acad Sci USA 89: 5537-5541, 1992.

18. Wilcox CS and Pearlman A: Chemistry and antihypertensive effects of tempol and other nitroxides. Pharmacol Rev 60: 418-469, 2008.

19. Volk T, Hensel M, Schuster H and Kox WJ: Secretion of MCP-1 and IL- 6 by cytokine stimulated production of reactive oxygen species in endothelial cells. Mol Cell Biochem 206: 105-112, 2000.

20. Cuzzocrea S, McDonald MC, Mota-Filipe H, Mazzon E, Costantino G, Britti D, Mazzullo G, Caputi AP and Thiemermann C: Beneficial effects of tempol, a membrane-permeable radical scavenger, in a rodent model of collagen-induced arthritis. Arthritis Rheum 43: 320-328, 2000.

21. Di Paola R, Mazzon E, Zito D, Maiere D, Britti D, Genovese T and Cuzzocrea S: Effects of Tempol, a membrane-permeable radical scavenger, in a rodent model periodontitis. J Clin Periodontol 32: 1062-1068, 2005.

22. Moosmann B and Behl C: Antioxidants as treatment for neurodegenerative disorders. Expert Opin Investig Drugs 11: 1407-1435, 2002.

23. Grasbon-Frodl EM, Kösel S, Riess O, Müller U, Mehraein P and Graeber MB: Analysis of mitochondrial targeting sequence and coding region polymorphisms of the manganese superoxide dismutase gene in German Parkinson disease patients. Biochem Biophys Res Commun 255: 749-752, 1999.

24. Schnackenberg CG and Wilcox CS: Two-week administration of tempol attenuates both hypertension and renal excretion of 8-Iso prostaglandin f2alpha. Hypertension 33: 424-428, 1999. 
25. Monti E, Supino R, Colleoni M, Costa B, Ravizza R and Gariboldi MB: Nitroxide TEMPOL impairs mitochondrial function and induces apoptosis in HL60 cells. J Cell Biochem 82: 271-276, 2001.

26. Offer T, Russo A and Samuni A: The pro-oxidative activity of SOD and nitroxide SOD mimics. FASEB J 14: 1215-1223, 2000.

27. Gariboldi MB, Rimoldi V, Supino R, Favini E and Monti E: The nitroxide tempol induced oxidative stress, p21WAF/CIP1, and cell death in HL60 cells. Free Radic Biol Med 29: 633-641, 2000.

28. Agarwal R and Kaye SB: Ovarian cancer: Strategies for overcoming resistance to chemotherapy. Nat Rev Cancer 3: 502-516, 2003.

29. Gariboldi MB, Lucchi S, Caserini C, Supino R, Oliva C and Monti E: Antiproliferative effect of the piperidine nitroxide TEMPOL on neoplastic and nonneoplastic mammalian cell lines. Free Radic Biol Med 24: 913-923, 1998.

30. Perrone GG, Tan SX and Dawes IW: Reactive oxygen species and yeast apoptosis. Biochim Biophys Acta 1783: 1354-1368, 2008

31. Circu ML and Aw TY: Reactive oxygen species, cellular redox systems, and apoptosis. Free Radic Biol Med 48: 749-762, 2010.
32. Todorova VK, Harms SA, Kaufmann Y, Luo S, Luo KQ, Babb K and Klimberg VS: Effect of dietary glutamine on tumor glutathione levels and apoptosis-related proteins in DMBA-induced breast cancer of rats. Breast Cancer Res Treat 88: 247-256, 2004

33. Alpert E, Gruzman A, Totary H, Kaiser N, Reich R and Sasson S: A natural protective mechanism against hyperglycemia in vascular endothelial and smooth-muscle cells: Role of glucose and 12-hydroxyeicosatetraenoic acid. Biochem J 362: 413-422, 2002.

34. Behrooz A and Ismail-Beigi F: Stimulation of glucose transport by hypoxia: Signals and mechanisms. News Physiol Sci 14: 105-110, 1999.

c) (i) () $€$ This work is licensed under a Creative Commons Attribution-NonCommercial-NoDerivatives 4.0 International (CC BY-NC-ND 4.0) License. 